\title{
INFÂNCIA, EDUCAÇÃO E LINGUAGEM EM MICHEL DE MONTAIGNE ${ }^{1}$
}

\author{
Flávia Rocha Carniel \\ Marcus Vinicius da Cunba
}

Resumo

Tomando por base o conceito de infância elaborado por Philippe Ariès, este artigo mostra que as manifestações de Michel de Montaigne sobre a educação de crianças são tipicamente modernas, pois se pautam no interesse psicológico e na preocupação moral. Utilizando metodologia fundamentada em conceitos da retórica, o artigo analisa os ensaios de Montaigne intitulados "Pedantismo" e "Da educação das crianças", destacando o valor atribuído pelo autor à linguagem e à comunicação entre aluno e professor. Destaca-se que Montaigne atribui o sucesso da docência às qualidades pessoais do professor, cuja sensibilidade pode ser desenvolvida pelo contato com as artes. As conclusões sugerem a necessidade de rever os conceitos educacionais vigentes na atualidade.

Palavras-chave: montaigne; infância; linguagem; retórica.

\section{CHILDHOOD, EDUCATION AND LANGUAGE IN MICHEL DE MONTAIGNE}

\begin{abstract}
Based on the concept of childhood developed by Philippe Ariès, this article shows that Michel de Montaigne's statements about the education of children are typically modern, as they are based on psychological interest and moral concern. Using a methodology based on concepts of rhetoric, the article analyzes Montaigne's essays entitled "Pedantism" and "On the education of children", highlighting the value attributed by the author to language and communication between student and teacher. It is noteworthy that Montaigne attributes the success of teaching to the personal qualities of the teacher, whose sensitivity can be developed through contact with the arts. The conclusions suggest the need to review current educational concepts.
\end{abstract}

Keywords: montaigne; childhood; language; rhetoric.

\section{INFANCIA, EDUCACIÓN Y LINGUAJE EN MICHEL DE MONTAIGNE}

\section{Resumen}

Partiendo del concepto de infancia desarrollado por Philippe Ariès, este artículo muestra que las manifestaciones de Michel de Montaigne sobre la educación de los niños son típicamente modernas, pues se basan en el interés psicológico y la preocupación moral. Utilizando una metodología basada en conceptos de retórica, el artículo analiza los ensayos de Montaigne titulados "Pedantismo" y "Sobre la educación de los niños", destacando el valor que el autor atribuye al lenguaje y la comunicación entre alumno y profesor. Es de destacar que Montaigne atribuye el éxito de la enseñanza a las cualidades personales del profesor, cuya sensibilidad se puede desarrollar a través del contacto con las artes. Las conclusiones sugieren la necesidad de revisar los conceptos educativos actuales.

Palabras clave: montaigne; infancia; lenguaje; retórica.

\footnotetext{
${ }^{1}$ Artigo derivado de pesquisa subsidiada pelo CNPq.
} 


\section{UMA CONCEPÇÃO MODERNA DE INFÂNCIA}

A publicação de História social da criança e da família (ARIÈS, 1981) representou um marco no ensino de História da Educação e no desenvolvimento da pesquisa nessa área no Brasil. Nas últimas quatro décadas, suas análises vêm sendo veiculadas e discutidas especialmente em cursos voltados à formação de professores, tanto na graduação quanto na pós-graduação. Sua influência sobre docentes e pesquisadores contribuiu para o estabelecimento de alguns consensos que já integram o senso comum: toda proposta educacional tem por base uma concepção acerca do que é ou deva ser a infância; o entendimento de uma teoria pedagógica torna-se sensivelmente facilitado quando se explicitam as ideias de seu autor sobre como são ou deveriam ser as relações entre as famílias e seus filhos.

As menções a Michel de Montaigne (1533-1592) no livro de Ariès têm o intuito de ilustrar a tese de que o período renascentista foi palco de lenta e complexa transição entre o fim da mentalidade vigente no medievo e o surgimento de uma forma tipicamente moderna de ver a infância. Inexistente na sociedade medieval, o sentimento da infância teve como uma de suas primeiras manifestações a paparicação, costume que consistia em exaltar os traços de "[...] ingenuidade, gentileza e graça" da criança, ser que se tornava, então, "[...] fonte de distração e de relaxamento para o adulto".

A maneira de ser das crianças deve ter sempre parecido encantadora às mães e às amas, mas esse sentimento pertencia ao vasto domínio dos sentimentos não expressos. De agora em diante, porém, as pessoas não hesitariam mais em admitir o prazer provocado pelas maneiras das crianças, o prazer que sentiam em "paparicá-las". (ARIÈS, 1981, p. 158)

Esse sentimento emergente gerou forte reação no final do século XVI, alastrando-se no século seguinte; “[...] pessoas rabugentas” passaram a ver como “[...] insuportável a atenção que se dispensava então às crianças” (ARIÈS, 1981, p. 162).

O primeiro sentimento da infância - caracterizado pela "paparicação" - surgiu no meio familiar, na companhia das criancinhas pequenas. $O$ segundo, ao contrário, proveio de uma fonte exterior à família: dos eclesiásticos ou dos homens da lei, raros até o século XVI, e de um maior número de moralistas no século XVII, preocupados com a disciplina e a racionalidade dos costumes. (ARIÈS, 1981, p. 163)

Um novo sentimento da infância já se articulava na mesma época, constituindo um padrão educacional que foi gradativamente ampliado no futuro, chegando à atualidade por intermédio do avanço científico e de concepções acerca da moralidade: "O apego à infância e à sua particularidade não se exprimia mais através da distração e da brincadeira, mas através do interesse psicológico e da preocupação moral" (ARIÈS, 1981, p. 162).

O ensaio de Montaigne intitulado "Da afeição dos pais pelos filhos" é citado por Ariès nesse contexto argumentativo para evidenciar a persistência, ainda no século XVI, da concepção tipicamente medieval que não atribuía valor às crianças pequenas por elas não poderem participar da vida dos adultos, em razão de sua excessiva fragilidade. Os pais pouco se importavam com os filhos pequenos por eles morrerem geralmente muito cedo devido à precariedade das condições sanitárias que atingia toda a população. "Perdi dois ou três filhos pequenos, não sem tristeza, mas sem desespero" - esse é o trecho de Ensaios transcrito por Ariès (1981, p. 157). 
Esse trecho, no entanto, não se encontra no ensaio indicado por Ariès. Ali, o máximo de proximidade com a referida transcrição é o que se lê na seguinte passagem:

Só duas vezes me bateram e ainda assim com muito cuidado. Teria agido da mesma forma com meus filhos, mas todos morreram cedo demais. Leonor, a única filha que não tive a infelicidade de perder em semelhantes circunstâncias, chegou à idade de seis anos - e mais - sem que se empregasse para puni-la de seus erros infantis [...] senão palavras, e bem anódinas. [...] O único resultado que pude constatar no emprego da vara ou do chicote foi tornar as almas mais covardes e mais obstinadas no mal. (MONTAIGNE, 1987, p. 183-184)

Como se pode notar, não há em Montaigne qualquer resquício da mentalidade medieval caracterizada por Ariès como afeita ao descaso pela morte das crianças - perdi dois ou três filhos, teria dito Montaigne. $\mathrm{O}$ que se percebe nitidamente é a expressão de um sentimento de tristeza pela morte prematura das crianças - morreram cedo demais, escreve Montaigne. Além disso, o trecho revela a contrariedade do pensador renascentista a métodos educacionais herdados do medievo, como o que valoriza a punição física dos pequenos.

A frase "Perdi dois ou três filhos pequenos, não sem tristeza, mas sem desespero" tem mais semelhança com a que se encontra no ensaio montaigneano intitulado "O bem e o mal só o são, as mais das vezes, pela ideia que deles temos", com a seguinte redação: “[...] perdi dois ou três filhos, em verdade ainda de peito. Conquanto eu não tenha morrido de dor, não deixou a coisa de me chocar. Trata-se aliás de uma das infelicidades a que o homem é mais sensível" (MONTAIGNE, 1987, p. 34). As palavras de Montaigne reafirmam aquele mesmo sentimento de tristeza, não indiferença, pela morte precoce de seus filhos, embora ele não se recorde precisamente de quantos se foram em tenra idade.

Outro trecho transcrito por Ariès do ensaio concernente à afeição dos pais pelos filhos ilustra com clareza a reação de Montaigne à paparicação:

[...] não sinto nenhuma simpatia por essas inclinações que surdem em nós independentemente da nossa razão. [...] não posso conceber que se beijem as crianças recém-nascidas ainda sem forma definida, sem sentimento nem expressão que as tornem dignas de amor. [...] Uma afeição sincera e justificável deveria nascer do conhecimento que nos dão de si e com esse conhecimento crescer, a fim de que então, se o merecerem, e desenvolvendo-se de par com o bom senso essa disposição para as amar, cheguemos a uma afeição realmente paternal. [...] Em geral, sentimo-nos mais comovidos com os trejeitos, os folguedos e as bobagens das crianças do que mais tarde com seus atos conscientes, e é como se delas gostássemos à maneira de símios e não de homens. (MONTAIGNE, 1987, p. 182)

Em suma, o autor de Ensaios exprime uma concepção da infância que não se alinha à mentalidade medieval, como também não compactua com a paparicação, e menos ainda se aproxima da simples rabugice de quem não suporta exacerbadas manifestações de afeto pelas crianças. Montaigne mostra-se partidário da tendência que Ariès (1981, p. 162) sugere ser dominante nos séculos vindouros: o valor conferido à infância vai se convertendo paulatinamente em uma educação norteada pelo "[...] interesse psicológico" e pela "[...] preocupação moral", mediante justificativa apoiada em preceitos racionais - tudo o que se firme "[...] independentemente da nossa razão" deixa de ter valor, diz Montaigne. 
Além do ensaio "Da afeição dos pais pelos filhos", a obra de Montaigne contém dois outros textos sobre temas educacionais - "Pedantismo" e "Da educação das crianças". Se no primeiro encontramos a explicitação de uma visão moderna da infância, nos demais é possível identificar reflexões que se aproximam de uma teoria pedagógica igualmente moderna. Dizemos que se aproximam, apenas, porque o estilo montaigneano não permite dizer mais do que isso. $\mathrm{O}$ autor não oferece teorizações formais aos assuntos que aborda, mas somente indagações e questionamentos; raramente expressa conclusões delineadas por uma tese filosófica unitária, sistematizada, pois o seu propósito é incentivar o exercício do pensamento sem apego a dogmas (SCHNEEWIND, 2005; COELHO, 2001; PATTIO, 2009).

$\mathrm{O}$ estilo montaigneano, unanimemente reconhecido como dubitativo e questionador, avesso a respostas diretas, pode ser atribuído à influência do ceticismo de Pirro de Élis (365-275 a.C.), cujas contribuições foram sistematizadas no início da Era Cristã por Sexto Empírico e amplamente divulgadas no Renascimento (HARTLE, 2005; EVA, 2007; WOLTER, 2007; BIRCHAL, 2007). A leitura de Ensaios revela que o autor, de fato, possui uma "[...] índole mutável e fluida, cheia de nuanças", mas, de acordo com Auerbach (2012, p. 150-151), caracterizar Montaigne como cético seria adotar uma "[...] sistematização demasiado estreita". Seja como for, é evidente que sua proximidade com o pirronismo não o impede de ultrapassar os limites da suspensão do juízo e articular reflexões propositivas valiosas para quem se interesse por examinar criticamente a educação no Renascimento e também as tendências educacionais de nosso tempo.

Este é o tema das próximas seções deste trabalho, nas quais analisaremos os ensaios de Montaigne que versam sobre educação. Para realizar essa meta, recorreremos a referenciais teóricos e metodológicos advindos da retórica, tanto a vertente derivada de Aristóteles revista por Perelman e Olbrechts-Tyteca (2002), quanto a que descende da Sofística em consonância com os desenvolvimentos de Crick (2010). Inicialmente, focalizaremos as relações entre linguagem e experiência em "Da educação das crianças". Na sequência, procuraremos extrair de "Pedantismo" propostas sobre como seria o educador segundo Montaigne.

\section{UMA LINGUAGEM EXPRESSIVA DA EXPERIÊNCIA}

Montaigne toma para si um problema bastante conhecido, tanto em sua época quanto na atualidade: a dificuldade sentida pelo educador diante das disposições típicas da criança, tão diferentes das disposições características do adulto. Crick (2010, p. 209) examina esse conflito utilizando dois conceitos próprios da retórica: as crianças veem o mundo com "[...] olhos kairóticos"; seu senso de tempo é curto, comparativamente à perspectiva de um homem centenário, por exemplo, que percebe uma crise, por mais aguda que seja, como "[...] simplesmente mais uma manifestação da mesma velha história que se resolverá ao longo do tempo", e por isso elogia o decoro. Como não há um olho divino para dizer quem está com a razão, Crick conclui que só nos resta a mesa de jantar para enfrentar a divergência entre as gerações.

O conceito de kairós é associado a uma percepção do tempo que se pode entender pela imagem metafórica de um rio cujo percurso oferece variadas situações imprevisíveis a quem nele se aventura. $\mathrm{O}$ nadador precisa estar atento ao aparecimento de repentinas intempéries e perigosos obstáculos e, por isso, adota uma conduta de pouco apego ou mesmo rejeição às normas estabelecidas. Os olhos kairóticos da criança captam o mundo com a urgência de quem precisa responder rapidamente a situações críticas aqui e agora. Na iconografia grega, o deus Kairós é representado por um jovem alado com cabelos que adornam somente a parte anterior da cabeça e 
carrega nas mãos uma balança equilibrada sobre o fio de uma navalha. O momento kairótico passa voando por nós e, se não o agarrarmos no momento certo, será impossível fazê-lo depois.

Decoro, por sua vez, é associado ao deus Chronos, imagem concernente a um tempo estável, linear, que flui sem atribulações, como se fosse um rio que segue tranquilo entre as margens, permitindo ao nadador movimentação segura, mergulhos profundos com retorno garantido à superfície. Crick (2010, p. 184) sintetiza a peculiaridade de chronos dizendo que "[...] a ação decorosa é apropriada para uma situação que se experimenta como parte de um todo contínuo e universal", em contraste com a ação kairótica, que se manifesta em contextos que parecem exigir "[...] exceção momentânea da regra". Os idosos elogiam o decoro por não sentirem o mundo ameaçado pela urgência, mas permeado pela solidez de um tempo que transcorre sem novidades.

Os dois rios, o kairótico e o decoroso, correm paralelamente na mesma direção, embora as águas de cada um deles envolva os respectivos nadadores de modos inteiramente distintos. A imagem da mesa de jantar utilizada por Crick para significar uma possível conexão entre educador e educando opera em nossa metáfora como um canal a ligar os dois rios. É o meio pelo qual o mais velho tenta persuadir o mais novo a abandonar suas vivências kairóticas para se render ao decoro. Se as diferenças entre ambos não forem resolvidas em família, o que é bastante comum acontecer, restará a sala de aula para alcançar essa meta, mas ali as chances de sucesso são igualmente pouco prováveis.

Seja no lar, seja na escola, a estratégia do educador decoroso consiste, na maioria das vezes, em tentar demover o outro de sua posição kairótica. Tanto para admoestar segundo padrões morais vigentes quanto para transmitir a experiência de quem já foi jovem e conhece os melhores caminhos a seguir na vida, o recurso educativo que mais se utiliza é a palavra, o discurso. Ocorre que a linguagem também é afetada pelas características típicas de decoro e kairós, o que torna muito difícil a possibilidade de acordo entre pessoas de diferentes gerações.

Um dos romances mais aclamados por expressar os sentimentos conflitantes de quem ingressa na vida adulta, $O$ apanhador no campo de centeio traz uma passagem bastante reveladora dessa dificuldade geracional. J. D. Salinger (s.d., p. 160-161) faz o Professor Antolini dizer ao rebelde Holden Caulfield:

[...] assim que você tiver uma ideia de onde quer chegar, seu primeiro passo vai ser aplicar-se no colégio. [...] Entre outras coisas, você vai descobrir que não é a primeira pessoa a ficar confusa e assustada, e até enojada, pelo comportamento humano. [...] Muitos homens, muitos mesmo, enfrentaram os mesmos problemas morais e espirituais que você está enfrentando agora.

São ensinamentos sábios, tentativa generosa de conduzir o garoto pelo estreito que leva à vida adulta, mas Holden apenas observa que "[...] é meio chato a gente ficar sentado, esperando uma pessoa dizer alguma coisa, enquanto ela está pensando. É duro mesmo. Fiquei me esforçando para não bocejar". Perseverante, Antolini continua sua preleção decorosa:

Há outra coisa que uma educação acadêmica poderá proporcionar a você. Se você prosseguir nela por um tempo razoável, ela acabará lhe dando uma ideia das dimensões da sua mente. Do que ela comporta e, talvez, do que ela não comporta. Depois de algum tempo, você vai ter uma ideia do tipo de pensamento que sua mente deve abrigar. [...] Você começará a conhecer as suas medidas exatas, e vestirá sua mente de acordo com elas. (SALINGER, s.d., p. 161)

São palavras de quem sabe como será o futuro por conhecer intimamente o deus Chronos, razão pela qual se julga capaz de dizer como será a mente do menino quando ele for diferente do 
que é hoje. Mas tudo o que vem do educador emoldurado em linguagem decorosa é pouco útil quando se nada em revoltas águas kairóticas. O romance termina provando essa tese: diante da insistência do psicanalista para saber se Caulfield pretende voltar ao colégio, o rapaz considera que "[...] isso é o tipo da pergunta imbecil. Quer dizer, como é que a gente pode saber o que é que vai fazer, até a hora que faz o troço" (SALINGER, s.d., p. 180 - grifo no original).

Em "Da educação das crianças", Montaigne tem um propósito prático: estabelecer um canal que interligue o rio kairótico e o rio decoroso, em resposta ao que foi solicitado pela Condessa Diana de Foix, preocupada em como educar a criança que em breve daria à luz. Montaigne (1987, p. 75-76) diz que as orientações que pode oferecer não passam de devaneios de quem teve pouco contato com as ciências, retendo delas apenas um "[...] aspecto mais geral e informe"; sua erudição é superada por "[...] qualquer menino das classes médias" porque o que expressa não passa de sentimentos e opiniões alteráveis a qualquer momento por novas experiências.

Assumindo o posicionamento kairótico de quem se diz "[...] mal instruído para instruir os outros", Montaigne (1987, p. 76) afasta-se das pretensões de sabedoria exibidas pelo Professor Antolini de Salinger. Suas ideias avançam em "[...] apalpadelas, cambaleantes", mas, por acreditar que a educação das crianças é "[...] a maior e a mais importante dificuldade da ciência humana", decide enfrentar o problema, e o faz apresentando "[...] ideias contrárias à opinião vulgar" (MONTAIGNE, 1987, p. 77). Após esses cuidadosos prolegômenos, bem fiéis a seu estilo, apresenta propostas que visam superar as limitações impostas pela dissonância entre kairós e decoro, em especial quanto ao privilégio conferido à linguagem.

O raciocínio de Montaigne opera por meio de dissociações nocionais que privilegiam termos relativos à experiência pessoal e à ação concreta, posicionando o mestre sempre acima da mera explanação verbal, teórica. A dissociação de noções é um recurso argumentativo que consiste em raciocinar por meio de pares conceituais antagônicos - nomeados Termo I e Termo II por Perelman e Olbrechts-Tyteca (2002) - que são hierarquizados no decorrer de um discurso, com predileção pelo segundo termo, permitindo ao orador estabelecer as suas escolhas na discussão do tema em pauta. Essa regra nem sempre é respeitada pelo autor de Ensaios, que muitas vezes prefere aproximar os termos em oposição.

O par fundamental utilizado por Montaigne é Saberes Emprestados (I) - Saberes Próprios (II). Embora os conhecimentos alheios sejam uma ferramenta decorosa de alto valor, empregada por ele mesmo com frequência, sugere que as fontes teóricas sejam sempre transformadas pelos saberes adquiridos por meio da experiência pessoal. Os conhecimentos cientificamente formalizados e os saberes que nos permitem aproveitar a vida são complementares, assim como Sabedoria (I) Honestidade (II), qualidades que não se desvinculam porque o segundo termo serve de guia para o primeiro.

$\mathrm{Na}$ verdade, equações nocionais de tal complexidade, envolvendo lições concernentes a valores morais, não se resolvem na esfera teórica, mas na prática, na ação. A criança traduzirá as lições "[...] em ações, e as aplicará aos atos de sua vida", e assim poderemos conhecer as suas virtudes, o seu temperamento e os seus gostos (MONTAIGNE, 1987, p. 85). A ação prática que institui o hábito é o componente central da reflexão educacional montaigneana, norteando a interação entre educador e aprendiz. O ensino por meio de gritos não estimula o discernimento, deve ser substituído pelo diálogo, mas não basta uma linguagem adequada, decorosa; é preciso propiciar experiências em que a criança consiga provar o que se formula discursivamente, escolher e discernir por si mesma. E a linguagem do educador deve ser expressiva dessas experiências para propiciar o desenvolvimento de aptidões valiosas, como a autonomia. Confirmando o propósito de, por esse método, construir um canal entre o rio kairótico e o decoroso, diz Montaigne (1987, p. 77): "É uma das mais árduas tarefas que conheço colocar-se a gente no nível da criança". 
A proposta montaigneana sugere não pedir ao aluno que repita palavras, mas que observe o modo como absorve os saberes e os aplica em sua vida. "O estômago não faz seu trabalho enquanto não mudam o aspecto e a forma daquilo que se lhe deu a digerir". O aluno está para o conhecimento, assim como o estômago está para o alimento; o conhecimento está para o aluno, assim como o alimento está para o estômago - qualquer que seja a analogia, a metáfora resultante remete à tese de que todas as lições devem ser digeridas pelo estudante, nada lhe sendo imposto por autoridade, e se restarem dúvidas, não há problema, pois "[...] somente os loucos têm certeza absoluta em sua opinião" (MONTAIGNE, 1987, p. 77).

Montaigne afasta-se o quanto possível de proposições decorosas e deixa-se envolver por kairós, o que se aplica à crítica que faz à assimilação mecânica de conhecimentos pela memória. Ao discorrer sobre as lições de diversos pensadores ensinadas ao aluno, metodologia comum na vida acadêmica da época, afirma que "[...] não se trata de aprender os preceitos desses filósofos, e sim de lhes entender o espírito”; “[...] saber de cor não é saber: é conservar o que se entregou à memória para guardar". Em troca, propõe valorizar os saberes advindos da experiência: “[...] para exercitar a inteligência tudo o que se oferece aos nossos olhos serve suficientemente de livro: a malícia de um pajem, a estupidez de um criado, uma conversa à mesa, são como outros tantos, novos assuntos" (MONTAIGNE, 1987, p. 78).

O valor conferido à ação, à experiência, à vivência pessoal, única, no que se incluem até mesmo supostas banalidades cotidianas, permeia as orientações educacionais montaigneanas, tendo por objetivo minimizar o hiato entre a criança e o adulto para formar integralmente o homem. Montaigne (1987, p. 84) sugere atividades lúdicas como a música, a dança, a caça etc., dizendo desejar que "[...] a delicadeza, a civilidade, as boas maneiras se modelem ao mesmo tempo que o espírito, pois não é uma alma somente que se educa, nem um corpo, é um homem: cabe não separar as duas parcelas do todo. Inovadora diante da ênfase das escolas de então em assuntos do espírito, essa ideia só se efetiva por meio do envolvimento do aprendiz em situações da vida real, muitas das quais apresentam embates de ideias e conflitos entre condutas. É assim que a criança aprenderá, por exemplo, a evitar "[...] atitudes indelicadas de dono do mundo, e a ambição pueril de querer parecer mais fino por ser diferente" (MONTAIGNE, 1987, p. 79). Trata-se de um aprendizado que podemos denominar primário, preparatório para ensinamentos secundários, como os que fazem parte do linguajar da ciência.

É preciso, primeiro, aprender a olhar para si mesmo, para sua própria experiência, entender a vida e desfrutar dela, para mais tarde, munido de discernimento e autonomia, embrenhar-se nos saberes formais: "Depois que lhe tiverem dito o que convém para o tornar mais avisado e melhor, falar-lhe-ão da Lógica, da Física, da Geometria, da Retórica; e como já terá a inteligência formada, logo aprenderá a ciência que escolher" (MONTAIGNE, 1987, p. 81). Decoro não se impõe sobre kairós sem mediação. A linguagem das coisas formais deve ser precedida por palavras que tenham respaldo na experiência imediata.

Antes das ciências, é importante que o aprendiz discuta com pessoas capazes de responder às suas indagações e questionamentos, e que aprenda a ceder perante adversários armados de bons argumentos. Saber admitir os próprios erros é um aprendizado primário, certamente útil para lidar com o conhecimento científico: “[...] teimar e contestar obstinadamente são defeitos peculiares às almas vulgares, ao passo que voltar atrás, corrigir-se, abandonar sua opinião errada no ardor da discussão, são qualidades raras, das almas fortes e dos espíritos filosóficos" (MONTAIGNE, 1987, p. 79). O aprendiz deve prestar atenção a tudo o que o cerca, diz Montaigne (1987, p. 80): “[...] tenho observado que, não raro, enquanto conversam à cabeceira da mesa acerca da beleza de uma tapeçaria ou do sabor do malvasia, bons ditos se perdem do outro lado". 
É valioso estimular a curiosidade por cenas cotidianas, mesmo aquelas consideradas banais; mais vale apreciar os fatos do que registrá-los; o mundo deve ser o livro do aluno, pois " [...] a infinita diversidade de costumes, seitas, juízos, opiniões, leis ensina-nos a apreciar sadiamente os nossos, a reconhecer suas imperfeições e fraquezas naturais, o que já não é pouco" (MONTAIGNE, 1987, p. 80-81). Nessas formulações, que bem sintetizam a proposta educacional de Montaigne, nota-se com evidência a hierarquização do par Saberes Alheios (I) - Saberes Adquiridos por Experiência Própria (II).

Não há, no entanto, desprezo pelo primeiro termo porque Montaigne aprecia decorosamente os bons argumentos de outrem, assim como os conhecimentos científicos que virão futuramente. O eixo de suas reflexões reside em decidir o que deve vir primeiro, o que se deve fazer para construir o canal que permita ao aprendiz interagir com os conhecimentos e valores da vida adulta. O educando não deve ser posto diante de um futuro que outros - como o Professor Antolini imaginam existir, mas ser instado a mergulhar no tempo presente, nas experiências reais que o cercam, pois a virtude é mais bem aproveitada por quem a pratica do que por quem somente a conhece pelos livros (MONTAIGNE 1987, p. 85).

Se o educando tem uma visão kairótica do mundo, e isto o inabilita a apreciar os conhecimentos e os valores alheios, Montaigne sugere que o meio para superar essa condição é a experiência, não a exortação verbal. Só a experiência viabiliza o desenvolvimento de um repertório de condutas morais, um vocabulário pessoal que expresse a individualidade e uma linguagem própria que habilite ao diálogo com saberes estranhos. A ação sobre o mundo imediato, sobre os acontecimentos da vida cotidiana, abre caminho para que o educando alcance patamares mais elevados de inteligência e, assim, tenha acesso a um rio diferente daquele em que se encontra.

\section{UM EDUCADOR DE CABEÇA BEM FORMADA}

A palavra pedantismo serve para designar pejorativamente pessoas que exibem conhecimento, cultura e erudição, quando na verdade não os possuem. A etimologia do vocábulo coincide com a do termo latino pedagogo, outrora utilizado para denominar o escravo que acompanhava as crianças às aulas (HOUAISS; VILLAR, 2001). No ensaio "Pedantismo", Montaigne incorpora o primeiro sentido da palavra ao segundo, com o propósito de mostrar que a instrução ministrada pelos professores de sua época servia apenas para acentuar disputas e promover vaidades entre os homens.

Para situar no tempo essas críticas, vale lembrar que o regime de estudos predominante na França de então era de responsabilidade dos Jesuítas, cujos objetivos e procedimentos eram familiares a Montaigne, ex-aluno de uma instituição da Companhia de Jesus fundada por Henrique IV em 1604, o Collège de la Flèche. A iniciativa educacional jesuítica teve início por volta de 1540 com o propósito de se opor à propagação do Protestantismo. Suas escolas seguiam o manual pedagógico Ratio Studiorum, ministrando latim, grego, gramática, matemática, teologia, filosofia e algumas ciências, sempre utilizando "[...] métodos predominantemente vergais e, em grande parte, memoristas e formalistas" (LUZURIAGA, 1963, p. 119).

Os educadores jesuítas incentivavam fortemente a competição entre os alunos, motivando cada um deles a se destacar perante seus pares e os dividindo em agrupamentos rivais. Luzuriaga (1963) caracteriza essa instrução como limitada ao estudo da história clássica com forte viés religioso, marcando distância entre os assuntos escolares e a vida real dos alunos e denotando sensível desprezo pelo caráter científico do conhecimento. A educação moral, por sua vez, era pautada na rígida imposição de normas de conduta, levando os estudantes a perderem a 
espontaneidade e a naturalidade na vivência cotidiana. Por fim, o regime didático jesuítico era pautado na dependência intelectual, desaconselhando qualquer iniciativa de senso crítico: o que estava pronto não devia ser questionado.

As críticas feitas por Montaigne em "Pedantismo" têm por alvo essa forma de ensino, da qual descende um tipo de mestre, o pedante decoroso. A dissociação nocional que orienta todo o ensaio é expressa pelo par Saber Superficial (I) - Saber Essencial (II), o qual se vincula diretamente ao já examinado Saberes Emprestados (I) - Saberes Próprios (II). Assim, o professor é visto como aquele que, utilizando os conhecimentos obtidos dos livros, só transmite uma sabedoria superficial, quando deveria fazer uso de saberes adquiridos por experiência própria para veicular conteúdos verdadeiramente significativos a seus alunos.

A rejeição de Montaigne aos mestres segue o questionamento que examinamos em nossa seção precedente: falta-lhes capacidade ou interesse para promover um ensino que tome por referência a ação. Apesar de os estudantes das escolas existentes serem vistos como doutos, não são capazes de atuar efetivamente no mundo real porque os seus educadores não os ensinam "[...] nem bem a pensar nem a agir" (MONTAIGNE, 1987, p. 73). Apoiando-se em Pacuvio, Montaigne (1987, p. 70) afirma: “[...] odeio esses homens incapazes de agir e cuja filosofia consiste unicamente em palavras".

Para descrever a sua proposta de como deveria ser o professor, o autor de Ensaios privilegia a segunda noção contida nos pares Palavra (I) - Ação (II) e Teoria (I) - Prática (II). Mas não sugere que esses termos possam existir de modo independente, pois nenhum deles é suficiente se não se fizer acompanhar por seu opositor. A teoria e a palavra são importantes, mas necessitam da prática e da ação para produzirem a elevação do homem: "[...] os filósofos, grandes pelo saber, maiores ainda o foram quando passaram à ação" (MONTAIGNE, 1987, p. 70). Não resta dúvida de que o professor proposto deva ser capaz de conjugar essas duas espécies de sabedoria, a que deriva de outrem e a que decorre de sua própria vivência.

A oposição elaborada pelo discurso montaigneano é, neste caso, Quantidade (I) Qualidade (II), seguindo o princípio de que vale mais "[...] quem sabe melhor e não quem sabe mais" (MONTAIGNE, 1987, p. 71). E esta observação aplica-se também às famílias: "[...] os cuidados e despesas de nossos pais visam apenas encher-nos a cabeça de ciência; de bom senso e virtude não se fala". Os genitores deveriam investir em contratar não doutores em ciências, para ensinar a seus filhos, mas mestres de valentia, prudência e justiça, para que as crianças pudessem assimilar prioritariamente o que a ciência não tem o dom de transmitir: os valores que formam os homens virtuosos (MONTAIGNE, 1987, p. 73).

Da oposição entre Quantidade e Qualidade derivam os pares Encher a Cabeça de Ciência (I) - Ensinar Virtudes (II) e Memória (I) - Consciência (II), com os quais Montaigne procura mostrar que, para entender o conhecimento científico é preciso possuir qualidades morais; caso contrário, o estudante permanecerá na superficialidade propiciada pela memorização, sem alcançar a devida compreensão dos conteúdos ministrados. Quando tal superficialidade impera, não ocorre nenhuma transformação no aprendiz, o que afeta igualmente o caráter de quem ensina: “[...] assim como os pássaros vão às vezes em busca de grão que trazem aos filhotes sem sequer sentir-lhe o gosto, vão nossos mestres pilhando a ciência nos livros e a trazendo na ponta da língua tão-somente para vomitá-la e lançá-la ao vento" (MONTAIGNE, 1987, p. 71). Tais professores são e permanecerão "[...] ignorantes das coisas essenciais da vida", "[...] presunçosos e insolentes" (MONTAIGNE, 1987, p. 70).

A preferência de Montaigne recai sobre um educador que tenha "[...] uma cabeça bem formada mais do que exageradamente cheia", que seja portador de melhores costumes e inteligência do que de ciência, e que exerça as suas funções de maneira inovadora (MONTAIGNE, 1987, p. 
77). A dissociação Cabeça Cheia (I) - Cabeça Bem Formada (II) é o alicerce da proposta montaigneana para a constituição do educador, o que se expressa também na oposição Ciência (I) - Bons Costumes e Inteligência (II). É preciso cuidado, porém, para não opor radicalmente tais noções. Montaigne afirma ser mais importante possuir valores sólidos e pensar por si mesmo do que repetir opiniões alheias, o que não implica recusa a interagir com as ideias dos outros. É assim, aliás, que ele mesmo procede na escrita de seu livro, servindo-se de inúmeros pensadores para confrontá-los com as suas próprias vivências.

Em suma, o que Montaigne renega não é o acesso a conhecimentos já firmados, mas a nossa incapacidade de ajustá-los a nós. Os mestres, portanto, deveriam ocupar-se não em transferir as ciências de um aluno a outro, mas em ensinar os estudantes a dialogar com os saberes científicos, dialogar consigo mesmos e com os demais interessados. Os mestres deveriam saber que é inútil a sabedoria dissociada da vida do aprendiz; que o que melhor se obtém dos conteúdos escolares é a transformação da alma: “[...] se a sua alma não se aperfeiçoa, se seus juízos não se tornam mais lúcidos, melhor fora que o estudante gastasse o tempo a jogar pela, pois ao menos o corpo ele o teria mais ágil". Se o conhecimento "[...] não modifica nem melhora o estado de imperfeição, fora certamente preferível não adquiri-lo" (MONTAIGNE, 1987, p. 72).

É notório o descontentamento de Montaigne com o saber doutoral que certos mestres ostentam de modo pedante, com arrogância, com o propósito exclusivo de exibir o que não possuem ou que possuem superficialmente. Sua intenção não é desvalorizar as letras em prol de conhecimentos advindos de rústicas práticas cotidianas, mas mostrar que o professor precisa ter mais do que livros em sua cabeça; o saber não é algo para encher a alma, mas para se incorporar a ela e alterá-la em cumplicidade com a experiência vivida (MONTAIGNE, 1987, p. 73).

Montaigne (1987, p. 72) inspira-se no homem comum para ilustrar sua crítica aos professores: "O camponês e o sapateiro vão vivendo simples e ingenuamente, falando do que conhecem; enquanto os outros por se quererem elevar e envaidecer de um saber todo superficial, que não lhes entrou sequer no cérebro, vão se embaraçando e chafurdando sem cessar". As pessoas simples são por ele valorizadas por causa de suas disposições perante a vida: elas não discutem sobre as coisas, elas agem sobre as coisas, e somente sobre as coisas que realmente conhecem. Os pedagogos são mestres em teoria, mas nenhum deles é capaz de a colocar em prática. Por isso, Montaigne os chama de lettresferus, termo francês que designa quem é golpeado pelas letras, abatido pelo saber superficial que ostenta.

Mas um homem de letras pode não ser assim golpeado. Para que não reste dúvida de que Montaigne não opõe, pura e simplesmente, o saber formalizado ao saber comum, vale mencionar sua apreciação das qualidades de Adriano Tourneboeuf, professor do Colégio de França:

\begin{abstract}
Nunca exercera outra profissão que não a de homem de letras, e na minha opinião em mil anos ninguém melhor do que ele mereceu lugar entre os primeiros. No entanto, não tinha nada de professoral [...] era dono da mais bela alma e eu o trouxe a assuntos alheios ao de seu comércio habitual. (MONTAIGNE, 1987, p. 72)
\end{abstract}

Esta avaliação sugere que professor e pedantismo podem não ser sinônimos, apesar de a etimologia aproximar os dois vocábulos. Logo no início do ensaio ora examinado, ao dar início à sua crítica aos professores, Montaigne (1987, p. 69) pergunta: “[...] como pode ocorrer que uma alma enriquecida de tantos conhecimentos não se torne mais viva e esperta, e que um cérebro vulgar e grosseiro armazene, sem apurar, as obras e juízos dos maiores espíritos que o mundo produziu?". Sugerimos inverter essa indagação e questionar se é possível haver uma alma tão enriquecida pela formação acadêmica que não seja pedante. Pode uma alma professoral manter-se 
DOI: $10.12957 /$ teias.2022.60978

disposta a ver o mundo com os olhos simples de um camponês ou de um sapateiro? Um professor pode possuir uma alma tão bela quanto a do mestre Tourneboeuf admirado por Montaigne?

\section{A FORMAÇÃO DO EDUCADOR MONTAIGNEANO}

A pergunta feita acima refere-se aos meios pelos quais se possa formar um educador que, apesar de moldado pelos cânones acadêmicos, tenha a cabeça bem formada; que não seja um mero exibidor de conhecimento decoroso, como o Professor Antolini, mas que sustente a disposição kairótica de olhar o mundo com inteligência aguda e envolvimento pessoal. Em suma, alguém que empregue a sua experiência para transitar pelo estreito que liga o rio calmo em que nadam os homens centenários e o rio turbulento em que se debate Holden Caulfield.

O autor de Ensaios pode nos ajudar na busca por uma resposta a essas indagações. Montaigne (1987, p. 72) acredita não bastar que "[...] as instituições não nos tornem piores, é preciso que nos façam melhores". As instituições que respondem pela formação do educador deveriam seguir esse princípio, mas costumam falhar, produzindo tão somente um profissional cheio de pedantismo decoroso. Montaigne, no entanto, é otimista, sugerindo haver "[...] naturezas fortes e retas [...] que assim se mantêm apesar das instituições defeituosas". O antídoto contra a incompetência institucional estaria, portanto, nas qualidades naturais de alguns indivíduos, não de todos. A conclusão é desagradável, mas inevitável: a grande maioria sucumbe à instrução doutoral que se ministra nas escolas de formação de professores.

A pergunta, então, persiste, pois o que nos interessa é justamente encontrar meios para formar aqueles que não possuem tais qualidades inatas. Formar pessoas como o próprio Montaigne, que, homem feito, cidadão bem resolvido, mantém a atitude kairótica de confrontar com leveza e liberdade os autores clássicos para construir uma narrativa que há séculos inspira leitores e leitoras de diferentes idades. Formar pessoas como Allan Karlsson que, no dia em que completava 100 anos, pulou a janela do asilo em que morava e andou em busca de novas aventuras. O personagem do romance de Jonas Jonasson (2013, p. 7) ilustra a possibilidade de um centenário manter-se ativo e intervir kairoticamente nos acontecimentos à sua volta: bem ao estilo de Montaigne, sem "[...] ponderar sobre qualquer coisa por muito tempo", ele recorre a saberes formais para agir com criatividade sobre o mundo.

Para responder à nossa pergunta, poderíamos investigar como se deu a educação de Montaigne e do personagem montaigneano de Jonasson, para que tenham conseguido transitar de um rio a outro, não se deixando oprimir pelo decoro, nem se atrapalhando nas águas revoltas de kairós. Manter o equilíbrio entre um e outro é o que qualifica a unidade estética da retórica (CRICK, 2010). A manutenção dessa unidade é o que permite ao educador desenvolver uma linguagem apta a dialogar com seus educandos, um vocabulário inovador que compartilhe com eles a profundidade do saber acadêmico, sustentando, ao mesmo tempo, a beleza e a vitalidade do olhar interrogativo e inconformista típico da infância e da juventude.

Crick (2010, p. 185) faz menção à “[...] loucura divina” que conduz as pessoas para além da racionalidade estrita do conhecimento livresco e as premia com a transcendência que abre caminho para "[...] a liberdade de imaginar a si mesmas, aos outros e ao mundo como maiores e mais belos do que talvez sejam e nunca serão". A esperança de nos tornarmos mais belos do que somos é ocasionada por essa loucura divina sugerida por Platão (1954), que no Fedro (244) faz Sócrates discorrer sobre a experiência inspirada pelas Musas, uma espécie de delírio que transporta “[...] uma alma virgem e ingênua" para "[...] um mundo novo e inspira-lhe odes e outros poemas que celebram as façanhas dos antigos e que servem de ensinamento às novas gerações”. 
A habilidade para encontrar nas artes elementos antigos que agradem também aos mais jovens. Talvez seja essa a resposta para nossa pergunta, que é também a dúvida formulada por Serva (2019, p. 3): "Por que as pessoas ficam caretas ao longo da vida? Porque sua capacidade de adotar novos hábitos e saborear novidades vai se reduzindo com o passar do tempo, como janelas que se fecham". E por que as janelas se abrem para uns - que "[...] parecem ser sempre jovens intelectualmente" - e não para outros? Serva analisa os resultados de pesquisas recentes sobre como procedem pessoas que, a exemplo de Montaigne e Karlsson, são tocadas pela loucura divina e pulam a janela que se abre ao novo. Uma das qualidades dessas pessoas é disposição para ouvir músicas de gêneros e autores variados. É o contato com a pluralidade estética das Musas o que as impede de ficar "caretas", o que lhes dá a chance de ser o canal que associa a esterilidade da vida adulta aos prazeres da juventude - ser uma verdadeira "metamorfose ambulante" cuja fala não repita monotonamente aquelas velhas opiniões formadas sobre tudo.

Mas o Sócrates de Platão (Fedro, 245) adverte que "[...] quem se aproxima dos umbrais da arte poética, sem o delírio que as Musas provocam, julgando que apenas pelo raciocínio será bom poeta, sê-lo-á imperfeito, pois que a obra inteligente se ofusca perante aquela que nasce do delírio". Para que seja efetivo o trabalho de formar o educador por intermédio do contato com as artes, fazse necessária a ação de um educador que reconheça essa característica da experiência estética. Parafraseando Dewey (2003), trata-se de propiciar aos aprendizes uma experiência singular que seja verdadeiramente educativa, que ultrapasse as barreiras que tornam o intelecto alienado do corpo.

Esta reflexão indica a urgência de revermos as nossas concepções teóricas, se desejarmos que nossas práticas educativas sejam condizentes com a experiência estética de desencadear a loucura divina, o delírio que abre a janela para o novo. Indica também uma trajetória de pesquisa que consiste em investigar como se deu a formação de indivíduos - não necessariamente artistas com evidente impacto no mercado das artes - cujas obras reconhecidamente contribuem para enriquecer a experiência de viver em coletividade.

\section{REFERÊNCIAS}

ARIÈS, Philippe. História social da criança e da família. 2. edição. Tradução Dora Flaksman. Rio de Janeiro: Zahar, 1981.

AUERBACH, Erich. Ensaios de literatura ocidental: filologia e crítica. 2. edição. Tradução Samuel Titan Jr. e José Marcos Mariani de Macedo. São Paulo: Duas Cidades/34, 2012.

BIRCHAL, Telma de Souza. O eu nos Ensaios de Montaigne. Belo Horizonte: UFMG, 2007.

COELHO, Marcelo. Montaigne. São Paulo: Publifolha, 2001.

CRICK, Nathan. Democracy and rhetoric: John Dewey on the arts of becoming. Columbia: University of South Carolina, 2010.

DEWEY, John. Art as experience. In: BOYDSTON, Jo Ann; HICKMAN, Larry (orgs.). The collected works of John Dewey, 1882-1953. The Later Works, v. 10: 1934. Electronic Edition, 2003.

EVA, Luiz Antônio Alves. A figura do filósofo: ceticismo e subjetividade em Montaigne. São Paulo: Loyola, 2007.

HARTLE, Ann. Montaigne and skepticism. In: LANGER, Ullrich. The Cambridge Companion to Montaigne. New York: Cambridge University, 2005. p. 183-206.

HOUAISS, Antônio; VILLAR, Mauro de Salles. Dicionário Houaiss da Lingua Portuguesa. Rio de Janeiro: Objetiva, 2001. 
JONASSON, Jonas. O ancião que saiu pela janela e desapareceu. Tradução Bodil Margareta Svensson. Rio de Janeiro: Record, 2013.

MONTAIGNE, Michel. Ensaios. Tradução Sérgio Milliet. São Paulo: Nova Cultural, 1987.

PATTTO, Julio Agnelo P. Dar vida às palavras: Montaigne em defesa de uma linguagem natural. Revista Filosofia Capital, Rio de Janeiro, v. 4, n. 8, p. 58-68, 2009.

PERELMAN, Chaïm; OLBRECHTS-TYTECA, Lucie. Tratado da argumentação: a nova retórica. Tradução Maria E. Galvão. São Paulo: Martins Fontes, 2002.

PLATÃO. Fedro. 3. edição. Tradução Jorge Paleikat. Porto Alegre: Globo, 1954.

SALINGER, Jerome David. O apanhador no campo de centeio. 12. edição. Tradução Álvaro Alencar, Antônio Rocha e Jório Dauster. Rio de Janeiro: Editora do Autor, s.d.

SERVA, Leão. Aquela velha opinião formado sobre tudo. Folha de S. Paulo, São Paulo, 27 out. 2019. Ilustríssima, p. 3.

SCHNEEWIND, Jerome B. Montaigne on moral philosophy and the good life. In: LANGER, Ullrich. The Cambridge Companion to Montaigne. New York: Cambridge University, 2005. p. 207-228.

WOLTER, Katarina Maurer. Um Estudo sobre a relação entre filosofia cética e criação ensaística em Michel de Montaigne. Doispontos, São Carlos, v. 4, n. 2, p. 159-170, out. 2007.

\section{Informações do(a)(s) autor(a)(es)}

Flávia Rocha Carniel

Colégio Bento Benedini, Ribeirão Preto/SP

flavia_r_c@hotmail.com

ORCID: https://orcid.org/0000-0002-4991-0959

Link Lattes: http://lattes.cnpq.br/8182391102213528

Marcus Vinicius da Cunha

Faculdade de Filosofia, Ciências e Letras de Ribeirão Preto da Universidade de São Paulo

marcusvc@ffclrp.usp.br

ORCID: http://orcid.org/0000-0001-8414-7306

Link Lattes: http://lattes.cnpq.br/5679422102387763 